\title{
5P Health Shield for BOP Citizens: A Self-Care Approach
}

\author{
Vandana Parvez ${ }^{1} \&$ Ravilochanan Parthasarathy ${ }^{2}$ \\ ${ }^{1}$ School of Management, SRM University, Kattankulathur, Tamil Nadu, India \\ ${ }^{2}$ School of Management, Faculty of Management, SRM University, Kattankulathur, Tamil Nadu, India \\ Correspondence: Vandana Parvez, SRM School of Management, SRM University, Kattankulathur, Tamil Nadu, \\ India. E-mail: shreprit@hotmail.com
}

Received: November 15, 2015

Accepted: January 20, 2014 Online Published: April 30, 2015

doi:10.5539/ass.v11n12p93

URL: http://dx.doi.org/10.5539/ass.v11n12p93

\begin{abstract}
Given the appalling health statistics of the Indian sub-continent, a study was conducted to understand how people could be incentivized to lead healthy lives. To this effect, six board categories of incentives were identified. The results of understanding the association between variables indicated that the incentive for behavior change pertaining to self-care had no correlation with the age and gender but education levels played a significant role. Respondents who were graduates and above indicated that professional involvement, community cooperation, information assimilation \& dispensing related support could improve their behavior pertaining to self-care. In corollary, individuals who are relatively less educated could be incentivized with therapeutic counselling, monetary incentives and family support. This study also highlighted the importance of women as the torch bearers of preventive healthcare and acknowledged their role in mobilizing the tenets of self-care. The need for an over-arching 5P Health Shield Program/Value Your Health Program is emphasized at a pan-India level. The former program is recommended for the less educated and marginalized while the later for the more educated and fortunate. All healthcare touch points like hospitals, nursing homes, primary care centres, private practices, pharmacies etc operating within the nation, should be mandated to assist in getting every Indian within the fold of either one of these Health Programs. Based on personal health scores/health parameters/risk factors, every Indian should be mapped to a specific health plan for eliciting the necessary guidance/support to prevent or predict the onset of health ailments, or else, protect or preserve oneself from its sinister outcomes. The program also proposes a partnership oriented plan for the chronically ill.
\end{abstract}

Keywords: preventive healthcare, 5P health shield program, Value your health program, lifestyle diseases, self care, therapeutic counseling

\section{Introduction}

As per NUHS, only $15 \%$ of Indian Urban Population is completely healthy. If the WHO statistics are to be considered, $60 \%$ of the world's heart patients are Indians with 1 in 4 struggling with diabetes. India's growing affluence is driving sharp increases in what were once considered scourges of the Western world: lung and breast cancer, obesity, diabetes, hypertension, and cerebro - and cardiovascular diseases. A rapidly changing lifestyle appears to be the one to be blamed, as Indians are smoking more; consuming more fat, sugar, salt, and refined grains; and leading increasingly sedentary lives, particularly in cities. Lifestyle related disorders like Type 2 diabetes, high cholesterol levels, hypertension, obesity, nerve compression etc are different from diseases because they are potentially preventable, and can be controlled with changes in diet, lifestyle and environment and hence these should be considered ailments rather than diseases. Although being mere disorders, these ailments should be considered sinister given the fact that they arguably cause or at the least, catalyze the onset of lethal diseases like cerebral \& cardiovascular diseases, renal failures, retinal detachments, cancer, arthritis, etc.

Controlling and containing the impact of these ailments through self-care measures is rather imperative.

The World Health Organization defines self-care as 'activities individuals, families, and communities undertake with the intention of enhancing health, preventing disease, limiting illness, and restoring health'.

Some of these behaviors include

- Seeking health related information

- Exercising 
- Seeing a doctor for regular checkups

- Making lifestyle changes by bringing about a work-life balance, stress reduction etc

- Adopting habits like 'no-smoking', moderation of alcohol intake, healthy eating etc

- Following low fat/sodium/carbohydrate diets

- Monitoring vital health signs

- Seeking advice through alternative care networks, evaluating this information, and making decisions to act upon it

\subsection{Research Motivation}

Although there is enough evidence to prove that India needs a lot more awareness about lifestyle diseases, but awareness alone is not sufficient to control the rampage of this sinister killer. Nor is it enough to just mobilize acceptance for the need to prevent or control the impact of these lifestyle diseases.

An overall integrated approach is mandatory whereby, apart from creating awareness about the disease itself, information is dispensed with regards to its development along with measures of prevention and control. In addition and most importantly people should be incentivized to lead healthy lives by adopting and adhering to the principles of self-care.

To this effect, an exhaustive study of literature and secondary research that was undertaken resulted in a long list of incentives that could possibly change human behavior pertaining to self-care. This extensive list was then grouped together under 6 board categories based on the existing literature and the final endorsement of 12 trained professionals working in the field of public health and behavior. The identified categories of incentives that could possibly change human behavior pertaining to self care were identified to be

- Therapeutic Counselling (Note 1)

- Monetary Incentives (Note 2)

- Professional Involvement (Note 3)

- Family Support (Note 4)

- Community Cooperation (Note 5)

- Info dispensing and assimilation (Note 6)

All of these provided a holistic framework for the study and was thus used as a threshold for this research.

\subsection{Explanation of Concepts}

Lifestyle Disorders/ailments - Type 2 diabetes, high cholesterol levels, hypertension, depression, nerve compression, obesity related issues etc.

Lifestyle Diseases - Cerebral \& cardiovascular diseases, Alzheimer's disease, Crohn's disease, nephritis, asthma, chronic liver disease or cirrhosis, renal failures, retinal detachments, cancer, arthritis, osteoporosis etc.

Pre-emptive Measures - Adopting healthy eating habits (timely intake of hygienically prepared nutritious food), adherence to a physical exercise routine (with a combination of brisk walking, floor exercises and muscle workouts), adapting medically recommended sitting posture, regularizing a medication regime etc.

Healthcare Behavior - Manifested in terms of awareness, attitude, adoption, adherence.

Therapeutic Counseling - Targeting, goal setting, and planning sessions in which patients and providers focus on a specific problem, set realistic objectives, and develop an action plan for attaining those objectives in the context of patient preferences and readiness.

Monetary Incentives - Bonuses, as incentives or rewards for health-related behavior.

Professional Involvement - Creation of a continuum of self-management training and support services, in which patients have access to services that teach skills needed to carry out medical regimens, guide health behavior changes, and provide emotional support.

Family Support - Cooperation from family members both emotional and physical to bring about change in health behavior.

Community Cooperation - Support from the community at large or ones organization to maintain work life balance and get the necessary online \& offline facilities for behavior change related to preventive care.

Info dispensing and assimilation - Active and sustained follow-up, in which patients are contacted at specified intervals to monitor health status, identify potential complications, provide health related knowledge, and check and reinforce progress in implementing the care plan. 


\subsection{Research Gaps}

Although there is evidence of quite a few studies dedicated to the assessment of intrinsic factors impacting self care behavior, the effect of extrinsic facilitators by way of incentives also needed focus.

Factors such as therapeutic counseling, monetary incentives, professional involvement, family support, community cooperation, information dispensing \& assimilation could arguably impact the self-care behavior of the urban masses. This was yet to be tested in the Indian context.

\subsection{Research Question}

The research gap brought forth a significant research question that needed to be addressed, which was: How about incentives - do they also play a role in shaping the self-care behavior of the Indian population? In line with these questions, the research objectives were formulated and are mentioned below.

\subsection{Research Objectives}

The core objective of this research was to assess the important incentives out of the six listed i.e. therapeutic counseling, monetary incentives, professional involvement, family support, community cooperation and information dispensing $\&$ assimilation, in the adoption of self-care behavior amongst urban dwellers.

\subsection{Hypothesis}

The adoption of self-care behaviour amongst urban dwellers is not dependent on incentives like therapeutic counseling, monetary incentives, professional involvement, family support, community cooperation and information dispensing \& assimilation.

\section{Method}

\subsection{Scope}

This study was carried out in MV Diabetic Hospital's Royapetta \& Adyar branches in Chennai.

\subsection{Justification of the Area Selected}

Chennai is an Indian metro with considerable representation in terms of the working population from almost all the Indian regions - hence this city was chosen for the study.

In addition, the city of Chennai has been termed India's health capital. Multi- and super-specialty hospitals across the city bring in an estimated 150 international patients every day. Chennai attracts about 45 percent of health tourists from abroad arriving in the country and 30 to 40 percent of domestic health tourists. The city has an estimated 12,500 hospital beds, of which only half is used by the city's population with the rest being shared by patients from other states of the country and foreigners (Note 7).

\subsection{Justification for Selecting MV Diabetics}

In Chennai, treatment for lifestyle related ailments like diabetics is available in government hospitals, private hospital and corporate hospitals, but in all of these hospitals, diabetic treatment is offered as one of the specialties.

M V Diabetic Centre was chosen for this study because it is a specialty hospital treating only lifestyle related ailments like diabetes. Moreover, over the years it has grown to be one of the largest referral centres for patients requiring super-specialists. It treated more than 2.4 lakhs people in the year 2011. Hence, decision of selecting this hospital for the collection of primary data.

\subsection{Period of Study}

For the purpose of this study and the objectives set, the primary data relating to the select age group was compiled during the calendar year 2013. As regards the secondary data, it was collected between calendar year 2010-2012.

\subsection{Sources of Data}

Majority of the data used in the research was primary in nature. Primary data was collected through a detailed survey. However the study also used some amount of secondary data- sources which has been duly included in the reference section below. Secondary information was sourced from published reports and also the internet, etc. The sources of secondary data have been listed in the reference section.

\subsection{Sampling Details}

Based on the fact that Chennai's average population is 50,00,000 - in order to achieve a confidence level of $95 \%$ and confidence interval of 5 , the ideal sample size calculated was approximately 382 . 
With reference to the objective set for this study, a structured questionnaire was designed, pretested and finalized. For the purpose of administering the questionnaire, the following methodology was adopted:

1. To ensure a fair coverage of the Chennai population, the survey was conducted in MV Diabetic Hospital's Royapetta \& Adyar branches. Care was taken to ensure that sample respondents belonged to all the 10 zones of corporation of Chennai [before extension of Chennai corporation limits].

2. From each zone, about 38 people were included in the survey.

Considering the nature of the study, a certain level of maturity amongst the respondents was considered, a precondition - hence individuals who had attained maturity (i.e. 18 years of age) were chosen as the lower end of the age group. Simple Random Sample was adopted as the sampling methodology.

\subsection{The Survey Process}

Given the nature of the study, Chennai's famous specialty hospital, MV Diabetic Hospital's Royapetta \& Adyar branches were chosen to identify the prospective respondents. The patients and their attendants entering the hospital were targeted. Once the patients had registered their visits and gone through their preliminary tests, they were approached and oriented to the various aspects of the study. Their willingness was assessed and then support sorted. In addition, since these patients would anyways have to wait to see their designated endocrinologist, resistance to respond to the questionnaire was minimal. Apart from a few, almost all the respondents eagerly read the questions before responding to them. It took almost 30 days to get all the 382 questionnaires filled in.

\subsection{Tools of Analysis}

The frequency analysis was used to examine the profile of respondents while the $t$ test for equality of means, for the identification of the fact whether the sample respondents differed significantly in terms of demographic factors like age, gender, and education.

The factor analysis helped to identify the relevant demographic factors like age, gender and education level influencing preventive $\mathrm{HC}$ behavior and the cluster analysis to identify the presence of different homogeneous groups in the sample. The multiple regression analysis provided support in identifying the important determinants of lifestyle related preventive healthcare behavior.

\section{Results}

\subsection{Frequency Analysis}

The Frequency analysis undertaken confirmed that $61.2 \%$ respondents are males, $77.4 \%$ were between the ages of $18-30 \mathrm{yrs}, 63.2 \%$ were post-graduates, $44 \%$ earned between INR $0-1$ Lakhs per annum, $35 \%$ used interactive media, $30 \%$ visual, $25 \%$ print, $10 \%$ used none. In terms of the social media membership, $81 \%$ used Facebook, $46 \%$ YouTube, $41 \%$ Orkut, 38\% LinkedIn and 34\% Twitter.

\subsection{Test for Hypothesis}

' $\mathrm{T}$ ' test was conducted to test various hypotheses relating to self-care behavior.

Hypothesis 1 - 'The incentives related to self-care behavior do not significantly differ among age groups.' While testing the hypothesis none of the incentives turned statistically significant. Therefore we accepted the null hypothesis that self-care behavior does not significantly differ among age groups.

Hypothesis 2 - 'The incentives related to self-care behavior do not significantly differ among genders.' While testing the hypothesis about the incentives of self-care behavior and gender, none of the incentives turned statistically significant. Therefore we accepted the null hypothesis that the incentives related to self-care determinants do not significantly differ among genders. In other words gender has no major impact on the incentives related to self-care behavior.

Hypothesis 3 - The determinants of self-care behavior do not differ significantly among respondents belonging to different educational background. The $t$ test revealed that education impacts three out of six incentives i.e. information assimilation \& dispensing, community cooperation and professional involvement. These incentives differ significantly among patients with different educational background. Thus the null hypothesis was rejected.

\subsection{Cluster Analysis}

Cluster analysis was carried out to find out whether the respondents could be divided into natural groupings based on the 6 incentives i.e. therapeutic counseling, monetary incentives, professional involvement, family support, community cooperation and info dispensing and assimilation. The outcome confirmed the existence of 5 
clusters. However, in Cluster 1, 2 and 3, since most of the respondents fell into one group with just 1 or 2 respondents in the others, those were not taken into account and were dropped. Only Cluster 4 and Cluster 5 were considered and proceeded with. It is worth noting that Cluster 5 had 3 distinct groups while Cluster 4 had only 2. Since Cluster4 Group1 attracted a significance value of $>0.05$, it was not considered in a line of good fit, hence dropped and only Group2 within Cluster 4 was considered. The 3 groups within Cluster 5 did not differ significantly in terms of the average of 6 variables. To test this, the average of these 6 variables and the variation among them were calculated and with that, the F value was computed. The results indicated that the mean of the 6 variables differed significantly among the 3 groups i.e. these 3 groups have distinct features.

Cluster Description is as below:

Cluster 4 Group 2

a) Age -18 to $30 \mathrm{yrs}-79 \%$

b) Gender - Male $63 \%$ and Female $37 \%$

c) Education - Post Graduation - 64\%

Cluster 5 Group 1

a) Age -18 to $30 \mathrm{yrs}-78 \%$

b) Gender - Male-53\%

c) Education - Post Graduation - 53\%

Cluster 5 Group 2

a) Age -18 to $30 \mathrm{yrs}-80 \%$

b) Gender - Male $61 \%$ and Female 39\%

c) Education - Post Graduation - 77\%

Cluster 5 Group 3

a) $\mathrm{Age}-18$ to $30 \mathrm{yrs}-76 \%$

b) Gender - Male $63 \%$ and Female $37 \%$

c) Education - Post Graduation - $60 \%$

The above findings substantiated the outcome of the test of hypotheses conducted earlier.

\subsection{Multiple Regression Analysis}

Multiple Regression Analysis was carried out in order to assess the impact of each of the incentives namely i.e. therapeutic counseling, monetary incentives, professional involvement, family support, community cooperation and info dispensing and assimilation on the dependent variable, i.e. general self-care within each of the clusters and its specific groups.

Cluster 4 Group 1 was dropped because of inappropriate fit.

Within Cluster 4 Group 2, the incentive 'Professional Involvement' was found to be statistically significant for the adoption of preventive healthcare behavior as indicated by the beta coefficient (.121) implying that 1 unit of improvement in belief/action relative to 'Professional Involvement' would improve the self-care behavior by .121 units.

Within Cluster 5 Group 1, the incentive, 'Information Dispensing \& Assimilation' was noted to be statistically significant for the adoption of preventive healthcare behavior as indicated by the beta coefficient (.139) implying that 1 unit of improvement in belief/action relative to 'Information Dispensing \& Assimilation' would improve the self-care behavior by .139 units.

Within Cluster 5 Group 2, the incentive 'Information Dispensing \& Assimilation was considered statistically significant for the adoption of preventive healthcare behavior as indicated by the beta coefficient (.281) implying that 1 unit of improvement in belief/action relative to 'Information Dispensing \& Assimilation' would improve the self-care behavior by .281 units.

Within Cluster 5 Group 3, the incentive 'Family Support' was considered statistically significant for the adoption of preventive healthcare behavior as indicated by the beta coefficient (.122) implying that 1 unit of improvement in belief/action relative to 'Family support' would improve the self-care behavior' by .122 units.

\section{Discussions}

The results of understanding the association between the variables indicated that the incentive for behavior change pertaining to self-care had no correlation with the age and gender of the respondents but education levels played a significant role. The outcome of cluster based regression analysis confirmed that. 
- Respondents who were graduates and above needed professional involvement, community cooperation and information assimilation \& dispensing related incentives to improve their behavior pertaining to self-care

- In corollary, individuals who are relatively less educated could be incentivized with monetary incentives, family support and therapeutic counselling to improve their behavior towards self-care

\section{Conclusion}

Given the fact that most educated adults in urban India have access, ability and appropriate attitude towards the use of electronic media, the Government of India should mandate the use of an integrated health platform by all hospitals, nursing homes, primary care centres, private practice centres, pharmacies etc. operating within the nation. It should be noted that the OPDs and emergency departments of these setups are also the primary touch points for millions of people who fall prey to the ill effects of leading unhealthy lives. The e-platform should enable the storage of health related data of each person/patient against their 'Adhar Card number' (similar to the National Security number prevalent in UK) wherein their lifestyle related ailment details, prescribed prevention related information, precaution plans, periodicity of checkups etc are recorded. The stored information should be linked to technology enabled rules facilitating the flow of automated sms/emails/recorded messages hypothetically referred to as 'Dost Ka Post' i.e. 'A Friend's Post', reminding them about their scheduled checkups, follow-on consultation sessions, task of monitoring \& logging health data etc. This platform should enable e-communication with regards to, say food consumption, exercise regime, stress management techniques, routine medication etc specifically customized to suit the individual's personal health conditions. It should also host a vibrant forum of online communities based on specific ailments where ideas can be exchanged, experiences shared, advice sort and counseling arranged. This platform can be designed and built on a PPP model (public private partnership) and these facilities could be offered on a SAS basis (software as a service) as a Cloud based mobile application for the convenience of the end user.

In contrast, a large number of India's less educated urban/rural citizens who belong to the 'Bottom of the Pyramid' (Prahalad \& Stuart, 2002) are economically weak. They spend most of their time trying to make two ends meet and have minimal or absolutely no access to technology. For these set of individuals, a one-on-one counseling approach is recommended, wherein professionals/health workers engage with them to set realistic targets related to their health parameters considered imperative to modulate risk factors and promote health.

In fact 160 million women in India who are primarily involved in care work and family rearing (Indian Census Data, 2011) should be engaged to create awareness and consciousness about the benefits of preventive healthcare. They should be mobilized to instill efficacy in self-care measures within their respective families especially amongst their young ones from an early age. Their contribution in terms of preparing nutritional meals with minimal salt, sugar and spices can be of immense benefit and hence should be capitalized upon. Campaigns aimed to sensitize and train them to inculcate healthy eating habits, exercise regimes, check-up schedules etc executed at the community and locality levels should provide the required impetuous to the nation's health related goals and objectives. These campaigns should be promoted with an emotional angle using nomenclatures such as 'Swasta Ka Saath' which in English means 'Companionship of Health'. Educational institutions should also be tapped for the purpose.

In addition, monetary initiatives which could be introduced among this segment in order to improve their behavior towards self care is sampled below:

a) An offer to exempt ' $\mathrm{X}$ ' amount of tax for achieving or complying with targets related to body weight, body mass, physical strength etc. could prove to be an effective incentive

b) Bonus or a partial cash refund on health insurance premiums can also be extended to this group of audiences to help improve their behavior towards self care

c) Discounts on gymnasium membership for maintaining a set of pre-determined targets related to health oriented risk factors, could also work as an incentive to improve self-care

These measures should stimulate a culture of self care, prevention, early detection and systematic monitoring \& control of lifestyle related ailments thus deterring, deferring and delaying the onset of the curative aspects of healthcare.

From a commercial perspective, the implementation of the proposed monetary schemes/incentives by insurance companies and wellness brands, could prove to be an effective acquisition strategy resulting in a dynamic customer base, providing cross-selling and up selling opportunities to a well oiled marketing machinery.

From a social standpoint, irrespective of the educational divide, an over-arching national 5P HealthShield Program/Value your Health Program is recommended. The former one for the less educated and marginalized 
while the later for the more educated and fortunate. All healthcare touch points for e.g. hospitals, nursing homes, primary care centres, private practice centres, pharmacies etc. operating within the nation, should be mandated to get every Indian within the fold of this national program. Based on health scores, every Indian should be aligned to a specific health plan, a brief description of which is as below.

- PREVENT PLAN - As the name suggests, this plan type should enrol individuals who have no known or indicative risk factors but are proactive about their wellness. For the members of this plan, efficacy related awareness towards preventive care should be reinforced vide an effective and integrated communications strategy

- PREDICT PLAN - This is targeted at off springs of say diabetics (especially of age group 50+), pre-diabetics, individuals who work in stressful/ demanding environments, are overweight, have high BMI indices, have $\mathrm{BP} /$ cholesterol related issues etc. - who may be quite susceptible or genetically predisposed to lifestyle related disorders. This group should be made aware of the impending risks and should be sincerely advised to adopt precautionary measures like reduction in weight, calorie consumption, mental stress, salt intake etc and should be encouraged to embark on a walking schedule, exercise regime, a high fiber-low calorie diet etc.

- PRESERVE PLAN - Individuals who have recently been diagnosed with one or many lifestyle related ailments like BP, high cholesterol, diabetes etc and need to be empowered with tools/ mechanism to preserve their vital organs from the deadly impact of these ailment, need to be mapped to this plan. Adoption and adherence to physical activity related regimes should be mandated especially for progressive ailments. Low salt, sugar and oil intake should be prescribed in order to reduce/maintain body weight. Counselling should be provided to help them cope with lifestyle related changes. Family members of this group should also be sensitized on these issues.

- PROTECT PLAN - This plan will look to map individuals with advanced level of lifestyle related ailments which ideally require an intensive approach to postpone or prevent complications. Given the chronic nature of such disorders, emphasis on innovative tactics especially to reduce depression and mental fatigue which is imperative to provide the required relief, should be incorporated as a part of this plan.

- PARTNER PLAN - Targeted at individuals engulfed with the complications of lifestyle related disorders, seeking support to protect their vital organs should be mapped to this plan. Vide this plan, members will be provided support by healthcare specialist with a partnership oriented approach.

These programs should reside on the technologically enabled 'National Health Platform' recommended earlier and should be integrated with the e-platform in discussion, for the tech savvy citizens. For the rest, manual support can be sort by NGO's, health workers etc for the execution of the recommended interventions and the promotion of campaigns discussed earlier.

Implementation of these measures could provide the right impetuous to the Indian government's vision of making health a social movement especially amongst citizens belonging to the 'Bottom of the Pyramid (BOP)'.

Taking a macro level view of the situation, it is recommended that other BOP nations especially the south Asian nations like Bangladesh, Pakistan, Srilanka etc who are genetically disposed to lifestyle related ailments(Note 8), could also use these strategies, plans and programs to build healthier nations.

\subsection{Limitations of the Research}

- The result of this study is confined to Chennai city and hence the results should be used as an indicator only. For the application of these incentives elsewhere - additional study will need to be conducted or this study will need appropriate modification.

- The sample is limited to the metropolitan population only. A better representation can be achieved by including the rural population.

- The statistical results of this research effort are subjected to the limitations of the respective tools that have been used.

\subsection{Indications for Future Research}

- This research effort should be extended to the non-urban/rural areas also. A comparative study of the outcome between the urban and rural regions could also turn out to be an interesting research area for other research scholars. In fact the outcome should be validated in other urban regions of this diverse country. In fact, given the health related statistics of rural India, further research is recommended in these pockets for a more holistic perspective.

- Similar studies can be undertaken with more incentives or sub-incentives.

- This research should also be conducted with the equal representation of the ill-literate section of the society. 


\section{Acknowledgements}

We wish to thank our families, colleagues, mentors and all our well wishers for having provided us the support to put this manuscript together.

\section{References}

Ablon, I. (1981). Stigmatized health conditions. Soc. Sci. Med., 15B, 5.

American Board of Internal Medicine: Clinical competence in internal medicine. (1979). Ann Intern Med., 90, 402-410.

Ann. (1969). Psychosocial aspects of disease. Intern. Med., 71, 1197-1206. Diagnostic and Statistical Manual of Mental Disorders (3rd ed.). American Psychiatric Association, Washington, 1980.

Beaglehole, R., \& Yach, D. (2003, September). Globalization and the prevention and control of non-communicable disease: the neglected chronic diseases of adults. The Lancet, 362 .

Boechner, L. S., Kohn, H., \& Rockwell, S. K. (1990). A Risk-Reduction Nutrition Course for Adults. Journal of The American Dietic Association, 90(February), 260-263.

Brody, D. S. (1980). Physician recognition of behavioural, psychological, and social aspects of medical care. Arch. Intern. Med., 140, 1286-1289.

Brown, J. B., \& Webster-Bogaert, S., Wetmore, S., Faulds, C., \& Stewart, M. (2002). The role of patient, physician and systemic factors in the management of type 2 diabetes mellitus. Family Practice, 19(4). Oxford University Press.

Brucks, M. (1985). The Effect of Product Class Knowledge on Information Search Behavior. Journal of Consumer Research, 12(June), 1-16.

Burns, A. C. (1992). The Expanded Health Belief Model as a Basis for Enlightened Preventive Health Care Practice and Research. Journal of Health Care Marketing, September, 32-45.

Celsi, R. L., \& Olson, J. C. (1988). The Role of Involvement in Attention and Comprehension Processes. Journal of Consumer Research, 15(September), 210-224.

Churchill, G. (1979). A Paradigm for Developing Better Measures of Marketing Constructs. Journal of Marketing Research, 26(February), 64-73.

Cigarette Smoking Among Adults-United States. (1994). Morbidity and Mortality Weekly Report, 45, 588-590.

Cohen, D. R. (1984). Utility Model of Preventive Behavior. Journal of Epidemiology and Community Health, 38(March), 61-65.

Commission on Chronic Illness: Chronic illness in the United States (1957, Vol. 1). Published for the Commonwealth Fund by Harvard University Press, Cambridge, Mass.

Congressional Report on Alcohol and Health. (1993). Alcoholism Report, 21(September), 1-2.

Does It Matter What You Weigh?. (1997, April 21). Newsweek, 58-64.

Enos, W. F., \& Beyer, J. (1953). Coronary disease among U.S. soldiers killed in action in Korea. JAMA, 152, 1090-1093.

Fletcher, S. W., Morgan, T., O’Malley, M., Earp, J. A., \& Degnan, D. (1989). Is Breast Self-Examination Predicted by Knowledge, Attitudes, Beliefs, or Sociodemographic Characteristics? American Journal of Preventive Medicine, 5(July/August), 207-215.

Fuerst, M. (1995). Do You Eat Right? Wrong?. American Health, 14(May), 4.

Gaski, J. F., \& Nevin, J. R. (1985). The Differential Effects of Exercised and Unexercised Power Sources in a Marketing Channel. Journal of Marketing Research, 22(May), 130-142.

Gelb, B. D., \& Gilly, M. C. (1979). The Effect of Promotional Techniques on Purchase of Preventive Dental Care. Journal of Consumer Research, 6(December), 305-308.

Gneezy, U., Meier, S., \& Pedro, R.-B. (2011, Fall). When and Why Incentives (Don't) Work to Modify Behavior. Journal of Economic Perspectives, 25(4), 191-210.

Gordon, R. S. Jr. (1963, March-April). Preventive Healthcare can be classified into Universal, Selective and Indicative for operational convenience. Report published by the Office of the Assistant Secretary for Health (US), 96(2), 107. 
Haggerty, R. I. (1980). Life stress, illness and social supports. Dev Med Child Neurol, 22, 391-400.

Harris, D. M., \& Guten, S. (1979). Health Protective Behavior: An Exploratory Study. Journal of Health and Social Behavior, 20(March), 17-29.

Hollenberg, C. H., \& Langley, G. R. (1978). The Canadian general internist: education and future role. Can. Med. Assoc. J., 118, 397-399.

Humanism and fact-finding in medicine. (1978). N Engi J Med., 299, 950-953.

Janz, N. K., \& Becker, M. H. (1984). The Health Belief Model: A Decade Later. Health Education Quarterly, 11(November), 1-47.

Jayanti, R. K., \& Burns, A. C. (1998). The Antecedents of Preventive Health Care Behavior: An Empirical Study. Journal of the Academy of Marketing Science, 26(1), 6-15.

Johnson, D. W., \& Johnson, R. T. (1985). Nutrition Education: A Model for Effectiveness, A Synthesis of Research. Journal of Nutrition Education, 17(June), S1-S44.

Jöreskog, K. G., \& Sorböm, D. (1989). LISREL 7: Users Reference Guide. Mooresville, IN: Scientific Software.

Kadowaki, T. New insights in the pathogenesis of obesity-linked insulin resistance and metabolic syndrome. Invited Speakers - IS0002 - Adiponectin - Department of Metabolic Diseases, Graduate School of Medicine, University of Tokyo, Tokyo, Japan IS0004.

Kasl, S. V., \& Cobb, S. (1966). Health Behavior, Illness Behavior, and Sick Role Behavior. Archives of Environmental Health, 12(February), 246-266.

Kobayash, K., Nishigaki, M., Abe, Y., Seki, N., Yokomuri, T., Yokoyama, M., \& Kazuma, K. (2008). Psychology Preventive behaviour in adult offspring of Type 2 diabetic patients and its relationship to parental advice. The Graduate School of Medicine, School of Health Sciences and Nursing, Department of Adult Nursing/Palliative Care Nursing, The University of Tokyo, Tokyo and Social Insurance Funabashi Central Hospital, Chiba, Japan Accepted 20 August 2008.

Korff, M. V., \& Gruman, J., Schaefer, J., Curry, S. J., \& Wagner, E. H. (1997, December 15). Collaborative Management of Chronic Illness. American Coltege of Physicians. Annals of internal Medicine, 127(12).

Kraft, F. B., \& Goodell, P. W. (1993). Identifying the Health Conscious Consumer. Journal of Health Care Marketing, Fall, 18-25.

Lipowski, Z. I. (1970). Physical illness, the individual and the coping processes. Psychiatry Med., 1, 91-102.

Lipowski, Z. I. (1981). Liaison psychiatry: referral patterns and their stability over time. Am. J. Psychiatry, 138, $1608-1611$.

Lwowslu, Z. J. (1983, May 1). Psychosocial Reactions to Illness. Canadian Medical Association I, 128.

Mechanic, D. (1962). The concept of illness behavior. J. Chronic Dis., 15, 189-194.

Moorman, C., \& Matulich, E. (1993). A Model of Consumers' Preventive Health Behaviors: The Role of Health Motivation and Health Ability. Journal of Consumer Research, 20(September), 208-228.

Nelson, D. L., Quick, J., \& Cambell. (2001). Corporate Warfare: Preventing Combat Stress \& Battle Fatique.

O'Donnel, M. (2004). Health-Promotion Behaviors That Promote Self-Healing. The Journal of Alternative and Complementary Medicine, 10(1).

O'Keefe, G. J., Boyd, H. H., \& Brown, M. R. (1998). University of Wisconsin-Madison, 53706, USA in their article. Who learns preventive health care information from where: cross-channel and repertoire comparisons. Health Commun, 10(1), 25-36.

Parsons, T. (1951). The Social System. Free Pr, Glencoe, Ill.

Petrie, A. (1978). Individuality in Pain and Suffering (2nd ed.). Chicago: Chicago U Pr.

Physical Activity and Health. A Report of the Surgeon General U.S. Department of Health and Human Services Centers for Disease Control and Prevention National Center for Chronic Disease Prevention and Health Promotion The President's Council on Physical Fitness and Sports.

Prabhakaran, D., \& Yusuf, S. (2010). Cardiovascular Disease In India: Lessons Learnt \& Challenges Ahead. Indian. J. Med. Res., 132(5), 529-530.

Raghuvanshi, P. V. (2013). Study on Healthy lifestyle Behaviour and Cardiovascular mortality among Urban \& 
Rural populations in India. International Journal of Lifescience Biotechnology \& Pharma Research, 2(1).

Reiser, M. F., \& Arieti, S. (1975). Physical illness, the patient and his environment. American Handbook of Psychiatry (2nd ed.), 4, 3-42. Basic, New York.

Reiser, S. J. (1978). Medicine and the Reign of Technology. New York: Cambridge U Pr.

Report on Physical Activity and Health. (1996). American Family Physician, 54(October), 1806-1808.

Rosenstock, I. M. (1966). Why People Use Health Services. Millbank Memorial Fund Quarterly, 3(P2), 94-127.

Rx: Take One Ounce of Prevention Daily. (1992). Modern Maturity, 35(6), 6.

Schimdt, H. Bonuses as Incentives and Rewards for Health Responsibility: A Good Thing? London School of Economics and Political Science, London, UK and Nuffi eld Council on Bioethics, London, UK

Schunk, D. H., \& Carbonari, J. P. (1984). Self-Efficacy Models. In S. M. Weiss, J. A. Herd, N. E. Miller, \& S. M. Weiss (Eds.), Behavioral Health: A Handbook of Health Enhancement and DiseasePrevention (pp. 230-247). New York: John Wiley.

Slaga, T. J., Sivak, A., \& Boutwell. R. K. (1978). Mechanisms of tumor promotion and cocarcinogenesis. Carcinogenesis - a comprehensive survey, 2. New York: Raven Press.

Smoking and health. (1964). Report of the Advisory Committee to the Surgeon General of the Public Health Service. PHS Publication No. 1103. U.S. Department of Health, Education, and Welfare, Washington, D.C.

Sørensen, J. B., Kragstrup, J., Kjær, K., \& Puggaard, L. (2007, March 2). BioMed Central BMC Health Services Research - Study protocol Exercise on Prescription: trial protocol and evaluation of outcomes. BMC Health Services Research, 7, 36. doi:10.1186/1472-6963-7-36

Sorenseni, J. B., Skovgaard, T., \& Puggaard, L. (2006). Exercise on prescription in general practice: A systematic review. Scandinavian Journal of Primary Health Care, 24, 69-74.

Strecher, V. J., \& Becker, M. H. (1988). Social Learning Theory and the Health Belief Model. Health Education Quarterly, 15(Summer), 175-183.

Strecher, V. J., DeVellis, B. M., Becker, M. H., \& Rosenstock, I. M. (1986). The Role of Self-Efficacy in Achieving Health Behavior Change. Health Education Quarterly, 13(Spring), 73-92.

Tully, S. (1995, June 12). America's Healthiest Companies. Fortune, 98-106. U.S. Department of Commerce.

World Health Organization. (2011, April). Global status report on noncommunicable diseases 2010 Description of the global burden of NCDs, their risk factors and determinants (p. 176).

\section{Notes}

Note 1. World Health Organisation's Western Pacific WHO director Shin Young-soo

Note 2. Korff, Michael Von et al., Collaborative Management of Chronic Illness 15 December 1997 Annals of Internal Medicine Volume 127 Number 12

Note 3. Schmidt, Harald, Bonuses as Incentives and Rewards for Health Responsibility: A Good Thing? Journal of Medicine and Philosophy , 33 : 198 - 220, 2008 doi:10.1093/jmp/jhn007 (C) The Author 2008

Note 4. Korff, Michael Von et al., Collaborative Management of Chronic Illness 15 December 1997 Annals of Internal Medicine Volume 127 Number 12

Note 5. Nishigaki, $M$ et al., Preventive behaviour in adult offspring of Type 2 diabetic patients and its relationship to parental advice. Journal compilation (C) 2008 Diabetes UK. Diabetic Medicine 25, 1343-1348

Note 6. Sørensen Jes B et al., Exercise on Prescription: trial protocol and evaluation of outcomes. BMC Health Services Research 2007, 7:36. http://dx.doi.org/10.1186/1472-6963-7

Note 7. Korff, Michael Von et al., Collaborative Management of Chronic Illness 15 December 1997 - Annals of Internal Medicine Volume 127 Number 12

Note 8. http://en.wikipedia.org/wiki/Medical_tourism_in_India

\section{Copyrights}

Copyright for this article is retained by the author(s), with first publication rights granted to the journal.

This is an open-access article distributed under the terms and conditions of the Creative Commons Attribution license (http://creativecommons.org/licenses/by/3.0/). 